\title{
C-reactive Protein and Early Mortality in Acute Ischemic Stroke
}

\author{
Dewan KR, Rana PVS \\ Department of Medicine and Neurology \\ College of Medical Sciences \\ Bharatpur, Chitwan Dist, Nepal.
}

\section{Corresponding author}

Khus Raj Dewan

College of Medical Sciences

Bharatpur, Chitwan, Nepal

Email: dewansantosh@yahoo.com

Citation

Dewan KR, Rana PVS. C-reactive Protein and Early Mortality in Acute Ischemic Stroke. Kathmandu Univ Med J 2011;36(4):252-5.

\begin{abstract}
Background

There is growing evidence that inflammation plays an important role in atherogenesis. Several studies have shown that C-reactive protein (CRP), an inflammatory marker, is associated with stroke severity and outcome. But limited studies are there which show the relationship of CRP with early mortality i.e within seven days.
\end{abstract}

\section{Objective}

To study the association of CRP within 24 hours after acute ischemic stroke onset with severity during admission, types of ischemic stroke and outcome.

\section{Methods}

This cross sectional study was done including 100 consecutive cases of acute ischemic stroke admitted to Neurology center of College of Medical Sciences, Bharatpur (Chitwan), Nepal. The cases were classified as per TOAST classification and severity at admission assessed using National Institutes of Health Stroke Scale. C-reative protein (CRP) level was estimated by latex particle agglutination test.

\section{Result}

Thirteen percent patients expired by 7th day. In the expired group, CRP was positive in 15.3 percent, 15.3 percent and 61.5 percent in patients with lacunar, cardioembolic and large artery atherosclerotic infarction respectively ( $p$ 0.19). CRP was positive in all 7 patients $(53.8 \%)$ who had expired with severe NIHS scale ( $p$ 0.004).

\section{Conclusion}

High CRP level is associated with stroke severity at admission and is an independent predictor of early seven day mortality after ischemic stroke

\section{KEY WORDS}

atherosclerosis, C-reactive protein, cardioembolic. ischemic stroke, lacunar

\section{INTRODUCTION}

Experimental and clinical evidence accumulated since 1990 have shown that inflammation plays a key role in atherogenesis. ${ }^{1}$ The most studied biomarkers of inflammation C-reactive protein (CRP) is an acute phase reactant protein which is produced predominantly by hepatocytes under the influence of cytokines i.e. interleukin (IL)-6 and tumor necrosis factor-alpha. It is markedly up regulated in atheromatous plaques where it promote LDL cholesterol uptake by macrophages, a key step in atherogenesis. ${ }^{2}$ CRP levels in high normal range have been shown to be a reliable measure of underlying systemic inflammation and predictor of future cardiovascular events in prospective cohort studies. ${ }^{3-5}$ As in coronary artery disease, there is increasing evidence that inflammatory process is being involved in cerebral ischemia as well and an elevated CRP levels may predict future ischemic stroke..$^{6-9}$ In metaanalysis of studies of long term follow up, Preindropil Protection Against Recurrent Stroke (PROGRESS) clinical trial and "Benzfibrate Infarction Prevention (BIP) Study" the figures for recurrent event was 1.7, 1.34 and more than two fold increased risk in highest versus lowest tertile group respectively. ${ }^{10-12}$ In addition, raised CRP levels may reflect the clinical course of the condition extent of brain infarction and an adverse prognosis. ${ }^{13-16}$ In all these studies focus was on mortality at one month and thereafter. No such data is available from Nepal. With this background, 
Table 1. Prevalence of CRP with the risk factors of stroke.

\begin{tabular}{|c|c|c|c|c|}
\hline \multirow[t]{2}{*}{ Risk Factors } & & \multirow{2}{*}{$\begin{array}{l}\text { No Cases } \\
\text { (\%) }\end{array}$} & \multirow{2}{*}{$\begin{array}{l}\text { CRP positive } \\
\text { No of cases }\end{array}$} & \multirow[b]{2}{*}{ Percentage } \\
\hline & & & & \\
\hline \multirow[t]{2}{*}{ Smoking } & yes & 66 & 41 & $62.1 \%$ \\
\hline & no & 34 & 22 & \\
\hline \multirow[t]{2}{*}{ Alcohol } & yes & 43 & 27 & $62.8 \%$ \\
\hline & no & 57 & 36 & \\
\hline \multirow[t]{2}{*}{ HTN } & yes & 72 & 46 & $63.8 \%$ \\
\hline & no & 28 & 17 & \\
\hline \multirow[t]{2}{*}{ DM } & yes & 19 & 11 & $57.9 \%$ \\
\hline & no & 81 & 52 & \\
\hline \multirow[t]{2}{*}{ CAD } & yes & 15 & 9 & $60 \%$ \\
\hline & no & 85 & 57 & \\
\hline \multirow[t]{2}{*}{ Dyslipidemia } & yes & 53 & 42 & $79.2 \%$ \\
\hline & no & 47 & 15 & \\
\hline Total & & 100 & $63^{*}$ & $63 \%$ \\
\hline
\end{tabular}

*CRP was positive in cases where risk factors were more than one.

the present study was undertaken to study the relation of CRP with severity and mortality in ischemic stroke.

\section{METHODS}

The present study was a cross sectional study which included 100 consecutive cases of first time ischemic stroke, admitted to Neurology Center of College of Medical Sciences (COMS), Bharatpur (Chitwan), during the period from November 2007 to April 2009. Written consent was taken from their relatives. All cases of hemorrhagic stroke, subarachnoid hemorrhage, TIA (Transient Ischemic Attack), brain tumor, and those having major systemic disorders and malignancy were excluded. Care was taken to exclude other causes associated with raised CRP. TOAST (Trial of Org 10172 in Acute Stroke Treatment) classification was used to classify the etiology of stroke as lacunar, cardioembolic and large artery atherosclerosis. ${ }^{17}$ Severity of stroke was categorized as mild (NIHS score less than 4), moderate (NIHS score 4 to 15) and severe (NIHS score $>15$ ) according to National Institute of Health Stroke (NIHS) Scale. ${ }^{18}$ The risk factors were identified in each case. None of the patients were thrombolysed. All the cases were treated according to the American Stroke Association's (ASA) guidelines. ${ }^{19}$ No neuroprotective drugs or vasodilators were used. All patients were put on deep vein thrombosis prophylaxis. The sample for CRP was taken at the time of admission and analyzed by qualitative rapid latex slide tests, based on the immunologic reaction between CRP as an antigen and latex particles coated with monospecific anti-human CRP. ${ }^{20}$ The data was analyzed using SPSS version 16. $p$ value was determined using Chi square test.

\section{RESULTS}

Relationship of CRP positivity to risk factors of stroke is shown in Table-1 and to stroke severity, type of the stroke and mortality in Table 2. In the present study CRP was positive in $79.2 \%$ in patients with dyslipidemia, $63.8 \%$ in patients with hypertension, $62.8 \%$ in alcohol consumers, $62.1 \%$ in smokers, $60 \%$ in patients with coronary artery disease and $57.9 \%$ in diabetic. CRP test was positive in $63 \%$ of cases studied and in $93 \%$ of cases who expired by seven days ( $p$ 0.01). In the discharged group, CRP was positive in $29.8 \%$ in patients with lacunar, $13.8 \%$ in patients with cardioembolic and $14.9 \%$ in patients with large artery atherosclerotic infarction. In the expired group, CRP was positive in $15.3 \%, 15.3 \%$ and $61.5 \%$ in patients with lacunar, cardioembolic and large artery atherosclerotic infarction respectively ( $p$ 0.19). The number of patients who expired having severe NIHS scale was 7/13 (53.8\%) and CRP positive in all the cases ( $p$ 0.004).

Table 2. Association of CRP with stroke severity, stroke etiology and stroke outcome.

\begin{tabular}{|c|c|c|c|c|c|c|c|}
\hline \multirow[t]{2}{*}{ Variable } & \multirow[t]{2}{*}{ No of cases } & \multicolumn{2}{|c|}{ Discharged cases $(n=87)$} & \multicolumn{2}{|c|}{ Expired cases $(n=13)$} & \multirow[t]{2}{*}{$\mathrm{X}^{2}$} & \multirow[t]{2}{*}{$\mathrm{p}$ value } \\
\hline & & CRP positive & CRP negative & CRP positive & CRP negative & & \\
\hline \multicolumn{8}{|l|}{ TOAST } \\
\hline Lacunar & 45 & $26(29.8 \%)$ & 17 (19.5\%) & $2(15.3 \%)$ & 0 & 3.32 & 0.19 \\
\hline Cardioembolic & 19 & $12(13,8 \%)$ & $4(4.6 \%)$ & $2(15.3 \%)$ & $1(7.7 \%)$ & & \\
\hline LAA & 36 & $13(14.9 \%)$ & $15(17.2 \%)$ & $8(61.5 \%)$ & 0 & & \\
\hline \multicolumn{8}{|l|}{ NIHSS } \\
\hline$<4$ & 29 & $11(12.6 \%)$ & $18(20.7 \%)$ & 0 & 0 & 11.04 & 0.004 \\
\hline $4-15$ & 53 & $35(40.2 \%)$ & $12(13.8 \%)$ & $5(38.4 \%)$ & $1(7.7 \%)$ & & \\
\hline$>15$ & 18 & $7(8.0 \%)$ & $4(20.7 \%)$ & $7(53.8 \%)$ & 0 & & \\
\hline \multicolumn{8}{|l|}{ Mortality } \\
\hline 7-day & 13 & - & - & $12(92.3 \%)$ & $1(7.7 \%)$ & 5.5 & 0.01 \\
\hline
\end{tabular}

*LAA-Large artery atherosclerosis.. 


\section{DISCUSSION}

Traditional methods for measuring serum CRP are available for use in patients with infectious and inflammatory disorders. ${ }^{21}$ These assays typically have a detection limit that in the range of 3 to $5 \mathrm{mg} / \mathrm{L}$, which is above the concentration observed in most apparently healthy individuals. High sensitivity methods for measurement of CRP (hs-CRP) detect concentrations down to $0.3 \mathrm{mg} / \mathrm{L}$. The assays are necessary for cardiovascular risk stratification, which is based upon discrimination of CRP levels extending below $3 \mathrm{mg} / \mathrm{L}$. This test is sensitized to detect CRP levels less $1 \mathrm{mg} / \mathrm{dl}$ (10micgm/ml). The latex slide test has the advantage of rapid performance, simple and cost effective in comparison to other tests for detection of CRP. ${ }^{22}$

In the present study a positive level of CRP was noted in 63 percent of cases studied. It was unrelated to the presence or absence of risk factors of obesity, smoking, alcohol abuse, hypertension, diabetes mellitus and coronary artery diseases. In "Benzfibrate Infarction Prevention (BIP) Study" which included 3122 cases of stable coronary heart disease (aged 45-74 years) and followed up for 6.2 years raised CRP levels was noted in high proportion of women and in those having risk factors for stroke. Only total and LDL cholesterol was not related to CRP levels. While the fasting blood glucose and triglycerides were directly related to CRP levels and an inverse relationship was noted with HDL cholesterol. ${ }^{12}$ However, in contrast to our studies where only 15 percent patient has coronary artery disease, all patients in BIP study had preexisting stable atherothrombotic cardiac disease.

Several studies have reported a significant relationship with the type of stroke and its severity. ${ }^{14-16}$ In this study CRP positive rate of 61.5 percent was found in patients having large artery atherosclerosis ( $p 0.19$ ) but $92.2 \%$ was noted in patients having moderate and severe neurological deficits ( $p$ 0.004) which showed a significant relationship with severity at presentation.

Nepal is a developing country with low per capita income where patient has to bear the cost of treatment, hence in our hospital there is a trend to go on early discharge. Thus, only data of early mortality can be reliably studied. Also, early worsening is common in stroke cases necessitating corrective measures to avoid short and long term adverse events. Hence in this study early mortality at seven day was studied and CRP was positive in $92 \%$ of the expired cases (p 0.01). However, studies reporting early mortality are few and have not studied the impact raised CRP on mortality. ${ }^{22-24}$ The studied quoted above had reported adverse impact of raised CRP on late mortality only. ${ }^{14-16}$

Di Napoli et al measured CRP levels in 193 patients of acute ischemic stroke at 24, 48 and 72 hours and at discharge and found that persistently elevated ( $>1.5 \mathrm{mg} / \mathrm{dl}$ ) or a increasing CRP values (crescendo pattern) at discharge predicted adverse prognosis and had strongest association with outcome at one year in a multivariate model. ${ }^{15}$ This pattern represented either an ongoing inflammatory process or the extension of cerebral lesion. Similar to our study, in this study patient with raised CRP had significantly lower Canadian Neurological Score Scale score and had large infarcts and cortical involvement.

The 'Bergen stroke study'(2009) concluded that high admission CRP level, when measured after 24 hours after the ictus, is significantly associated with etiology, stroke severity functional outcome and with late mortality. ${ }^{16}$ But unlike our study, the patients with high CRP value had a higher frequency of stroke of cardioembolic origin and early mortality was not studied.

Inspite of small number of cases studied within 18 months and non-availability of the test for detecting highly sensitive CRP levels (hSCRP), our findings supported the previous observations that an elevated CRP reflects the severity and the extent of brain infarct.and is related to early mortality. ${ }^{9,14-16}$ CRP can thus be added to the list of predictor of prognosis in ischemic stroke as its levels are affected little by other factors than inflammation, its risk prediction is independent of other known cardiovascular risk factors, and highly sensitive reproducible assays are now available. A study over longer period and involving large number of patient with quantitative estimation of serum CRP levels following the guidelines of Centers for Disease Control and Prevention and the American Heart Association (CDC/AHA) is needed for detection of high risk values for prediction of ischemic stroke and for predicting mortality following stroke. ${ }^{3}$

\section{CONCLUSION}

High CRP level is associated with stroke severity at admission and is an independent predictor of early seven day mortality after ischemic stroke.

\section{ACKNOWLEDGEMENT}

We thank the Ethical Commete of College of Medical Sciences for letting us do this research work and publish this paper. We also thank Mr Naresh Manandhar for his opinion in analytic part.

\section{REFERENCES}

1. Libby P. Inflammation in atherosclerosis. Nature 2002;420:868-74.

2. Torzewsky M, Rist C, Mortensen RF, Zwaka TP, Bienek M, Waltenberger $J$ et al. $C$ reactive protein in arterial intima: role of C-reactive protein receptor dependant monocytic recruitment in atherogenesis. Atheroscler Thromb Vasc Biology 2000;20:2094-9.

3. Pearson TA, Mensah GA, Alexander RW, Anderson JL, Cannon RO III, Criqat $\mathrm{M}$ et al. Markers of inflammation and cardiovascular disease: application to clinical and public health practice: a statement for health care professionals from the Centers for Disease Control and Prevention and the American heart Association. Circulation 2003;107:499-511. 
4. Rothwell PM, Howard HC, Power DA, Guntikow SA, Algra A, van Gijn $J$ et al. Fibrinogen concentration and risk of ischemic stroke and ischemic eventsin 5113 patients with transient ischemic attacks and minor ischemic stroke. Stroke 2004;35:2300-5.

5. Di Napoli M, Schwaninger M, Campbell R, Ceccarelli E, Di Gianfilippo G, Donatti $C$ et al. Evaluation C Reactive protein measurement for assessing the risk and prognosis in ischemic stroke : a statement for health care professionals from the CRP Pooling Project members, Stroke 2005;36:1326-9.

6. Arvin B, Neville LF, Barone FC, Feuerstein CZ. Role of inflammation and cytokines in brain injury. Neurosci Biobehav Rev 1996;20:445-52.

7. Lagrand WK, Visser CA, Hermens WT, Niessen HWM, Verheugt FWA, Wolbink G-J et al. C-reactive protein as a cardiovascular risk factor: more than epiphenomenon. Circulation 1999;100:96-102.

8. Koening W, Sund M, Frohlich M. C- reactive protein a sensitive marker of inflammation predicts future risk of coronary heart disease in initially healthy middle aged middle aged men: resault from MONICA (Monitoring Trends and Determinants Cardiovascular Disease) Augsburg. Cohort Study 1984-1992. Circulation 1999;99:237-42.

9. Ridker PM, Hennekens $\mathrm{CH}$, Buring JE, Rifal N. C-reactive protein and other markers of inflammation in the prediction of cardiovascular disease in women. N Eng J Med 2000;342;836-43.

10. Kuo HK, Yen CJ, Chang CH, Kuo CK, Chen JH, Sorond F. Relation of C-reactive protein to stroke, cognitive disorders and depression in the general population: systemic review and meta-analysis. Lancet Neurol 2005;4:371-80.

11. Woodward M, Lowe GDO, Camp bell DJ, Colman S, Rumley A, Chalmers $J$ et al. Association of inflammatory and hemostatic variables with the risk of recurrent stroke. Stroke 2005;36:2143-7.

12. Tanne D, Benderly M, Goldbourt U, Haim M, Tenenbaum A, Fisman EZ et al. C-reactive prtein as a predictor of Incident ischemic cerebrovascular sdtroke among patients with preexisting cardiovascular disease. Stroke 2006;37:1720-4.

13. Hansson H. Mechanisms of disease: Inflammation, atherosclerosis and coronary artery disease. N Eng J Med 2005;352:1685-95.
14. Muir KW, Weir CJ, Alwan W, Squire IB, Lees KR. C-Reactive Protein and Outcome after Ischemic Stroke. Stroke 1999;30:981-5.

15. Di Napoli M, Gianfilippo G, Sollecito A, Bocola V. C reactive protein and outcome after first ever ischemic stroke. Stroke 2000;31:238-9.

16. Idicula TT, Brogger J, Naess $H$, Waje-Andreassen $U$, Thomassen L. Admission C - reactive protein after acute ischemic stroke is associated with stroke severity and mortality: The 'Bergen Stroke Study' BMC. Neurology 2009;9:18-26.

17. Adams HP Jr, Davis PH, Leira EC, Chang KC, Bendixen BH, Clarke WR et al. Baseline NIH Stroke Scale score strongly predicts outcome after stroke: a report of the Trial of Org 10172 in Acute Stroke Treatment (TOAST). Neurology 1999;53:126-31.

18. Clark WM, Hourihane JM.: Clinical Stroke Scales. In: Harndon RM (ed). Handbook of Neurologic Rating Scale. Demos Vermande. New York. 1997;7:161-86.

19. Adams HP, del Zoppo G, Alberts MJ, Bhatt DL, Brass L, Furlan A et al. Guidelines for the early management of Adukts with ischemic stroke: A guideline from the American Heart Association / American Heart Association ouncil, Clinical Cardiology Councila, Cardiovascular Radiology and intervention Counciland the Atherosclerotic Peripheral vascular Disease and Quality care Outcomes in research Interdisciplinary Groups. Stroke 2007;38:1655-711.

20. Schalla WO, Arko RJ, Thompson SE. Evaluation of a C-reactive protein latex agglutination detection test with sera from patients with sexually transmitted diseases. J Clin Micro.1984 20:1171-3.

21. Gabay C, Kushner I. Acute-phase proteins and other systemic responses to inflammation. NEJM 1999;340:448-54.

22. Glader EL, Stegmayr B, Norrving B, Teren A, Hulter- Asberg A, Wester $P O$ et al. Sex difference in management and outcome after stroke. A Swedish national prospective study. Stroke 2003;34:1970-5.

23. Semplicini A, Maresca A, Boscolo G, Sartori M, Rochi R, Gisntin V et al. Hypertension in acute ischemic stroke. A compensatory mechanism or an additional damaging factor? Arch Intern Med 2003;163:211-6.

24. Saposnik G, O’Donell M, Fang J, Hachinski V, Kapral MK. Variable associated with 7-day, 30-day and 1year fatality after Ischemic Stroke. Stroke 2008;39:2318-24. 